\title{
Composición y abundancia de áfidos y la aplicación de aceites minerales en el progreso epidémico del virus de la mancha anular del papayo (PRSV-P)
}

\author{
Félix Valera Jardines ${ }^{1}$ / José Antonio Mora-Aguilera² / Juan Antonio Villanueva Jiménez ${ }^{3}$ / \\ Daniel Téliz Ortiz ${ }^{4} /$ Adrián Vega Piña ${ }^{5}$
}

Recepción: 14/10/2019 Aceptación: 19/03/2020

\begin{abstract}
Resumen
El virus de la mancha anular del papayo es un factor limitante para la producción de papaya en Michoacán, México. Se evaluó el efecto de la aspersión semanal de los aceites minerales citrolina y Saf-T-Side ${ }^{\circledR}$ sobre la incidencia visual y serológica del virus de la mancha anular del papayo, en una plantación de papayo cv. Maradol roja en Antúnez, Michoacán.
\end{abstract}

No se registraron diferencias significativas ocasionadas por las aplicaciones de aceites minerales respecto al testigo. Sin embargo, la incidencia visual y serológica exhibió resultados contrastantes a los 32 y 60 días. Las epidemias en el testigo se describieron mediante el modelo de Weibull $\left(\mathrm{r}^{2}=0.97, \mathrm{c}=5.17 \mathrm{y} \mathrm{b}^{-1}=0.013\right)$. El área bajo la curva de la enfermedad $(\mathrm{ABCE})$ fue de 6087 días porcentaje y la incidencia final (Yf) de $98 \%$.

Se colectaron 309 adultos alados de 17 especies de áfidos en trampas tipo Moericke. Las trampas amarillas capturaron $60 \%$ y las verdes $40 \%$; con diferencias significativas $(\mathrm{P}<0.05)$ por especie, respecto al color de trampa. Únicamente Myzus persicae exhibió diferencia significativa en la captura de áfidos potencialmente vectores de la mancha anular del papayo, causada por el color de trampa.

Con base en la incidencia de la mancha anular del papayo, M. persicae $(\mathrm{r}=0.8)$, Aphis nerii $(0.7)$ y A. spiraecola $(0.7)$ estuvieron significativamente correlacionadas. Sin embargo, no se encontró correlación entre variables meteorológicas e incidencia.

Palabras clave: Epidemiología, Potyvirus, citrolina, Saf-T-Side ${ }^{\circledR}$

\begin{abstract}
The papaya ringspot virus is a limiting factor for papaya production in Michoacán, Mexico. The effect of the weekly spraying of citroline and Saf-T-Side mineral oils on the visual and serological incidence of the papaya ringspot virus was evaluated in a papaya plantation cv. Red Maradol in Antúnez, Michoacán.

There were no significant differences caused by the applications of mineral oils with respect to the control. However, the visual and serological incidence exhibited contrasting results at 32 and 60 days. The epidemics in the control were described using the Weibull model $(\mathrm{r} 2=0.97, \mathrm{c}=5.17$ and $\mathrm{b}-1=0.013)$. The area under the disease curve (ABCE) was 6087 percentage days and the final incidence (Yf) was $98 \%$.

309 winged adults of 17 aphid species were collected in Moericke-type traps. The yellow traps captured 60\% and the green ones 40\%; with significant differences $(\mathrm{P}<0.05)$ by species, regarding the trap color. Only Myzus persicae showed a significant difference in the capture of aphids potentially vectors of the papaya ringspot, caused by the trap color.
\end{abstract}

Based on the incidence of papaya ringspot, M. persicae $(\mathrm{r}=0.8)$, Aphis nerii $(0.7)$ and A. spiraecola (0.7) were significantly correlated. However, no correlation was found between meteorological variables and incidence.

Key words: Epidemiology, Potyvirus, Citroline, Saf-T-Side ${ }^{\bullet}$

1. Maestro en Ciencias, Gerente de Regulación y Cumplimiento Normativo, Síntesis y Formulaciones de Alta Tecnología, S.A. de C.V., Tlalnepantla de Baz, México; email: vajf73@hotmail.com; ORCID: http://orcid.org/ 0000-0002-2591-0225

2. Doctor en Ciencias, Profesor-investigador, Colegio de Postgraduados, Campus Montecillo, Programa de Fitosanidad-Fitopatología, Texcoco, México; email: aguilera@colpos.mx; ORCID: https://orcid.org/0000-0002-6652-0979

3. Philosophy Doctor, Profesor-Investigador Titular, Colegio de Postgraduados, Campus Veracruz, Programa de Agroecosistemas Tropicales, Veracruz, México. Autor para correspondencia; email: javj@colpos.mx; ORCID: http://orcid.org/ 0000-0003-0668-3466

4. Philosophy Doctor, Profesor-Investigador Emérito, Colegio de Postgraduados, Campus Montecillo, Programa de Fitosanidad-Fitopatología, Texcoco, México; email: dteliz@colpos.mx; ORCID: https://orcid.org/0000-0001-9427-2960

5. Doctor en Ciencias, el investigador participó en la investigación actualmente está jubilado, México; ORCID: http://orcid.org/ 0000-0001-6865-0710 


\section{Introducción}

El papayo (Carica papaya L.) es afectado por diversos agentes parasíticos que limitan su producción y comercialización (GIP, 1995). La principal enfermedad en las diferentes regiones papayeras de México es la Mancha Anular del Papayo, inducida por el virus de la mancha anular del papayo (Papaya Ringspot Potyvirus type-P, PRSV-P) ${ }^{6}$ (Hernández-Castro et al., 2015). Aunque el virus puede trasmitirse mecánicamente, su principal forma de transmisión es de manera no persistente, por medio de áfidos (Hemiptera: Aphididae).

Los principales vectores reportados en plantaciones de papayo en México son Aphis gossypii, A. nerii, A. spiraecola, Macrosiphum euphorbiae y Myzus persicae (Mora-Aguilera et al., 1993; Villanueva-Jiménez y Peña-Martínez, 1991). El síntoma inicial del PRSV-P en campo varía en tiempo de aparición y fluctúa entre 15 y 30 días, posteriores a la infección (Cárdenas-Soriano y Téliz-Ortiz, 1992).

El Grupo Interdisciplinario del Papayo $(\mathrm{GIP})^{7}$ del Colegio de Postgraduados, así como investigadores del Instituto Nacional de Investigaciones Forestales Agrícolas y Pecuarias (INIFAP) generaron propuestas técnicas para reducir las pérdidas ocasionadas por el PRSV-P (Becerra-Leor y De León-Maycotte, 1991; GIP, 1992, 1994 y 1995). Los componentes evaluados por el GIP en Veracruz y Michoacán para el manejo integrado del Papayo (MIP) ${ }^{8}$ fueron: Protección de vivero con malla antiáfidos, barreras vegetales de maíz (Zea mays) y jamaica (Hibiscus sabdariffa), densidades altas de plantación (2200 a 4444 plantas/ha); eliminación temprana de plantas con síntomas iniciales del PRSV-P y aspersión de aceites de origen vegetal y mineral (Rivas-Valencia et al., 2008; Hernández-Castro et al., 2003, 2004, 2010 y 2015). No obstante, que el MIP ha promovido resultados satisfactorios en productividad, se debe analizar el efecto individual de cada uno de los componentes técnicos en diversas localidades para seleccionar los más eficientes y reducir costos.

Los aceites minerales y vegetales han sido dirigidos a formar una película sobre el follaje, que permita "limpiar" el estilete de los áfidos alados que arriban al cultivo y que portan este virus no-persistente (Harris y Maramorosch, 1977; Mosqueda-Vásquez et al., 1990; Villanueva-Jiménez et al., 2019). Rivas-Valencia et al. (2008) evaluaron el efecto de aspersiones del aceite mineral citrolina al 1.5\% en Michoacán, respecto a las epidemias inducidas por el PRSV-P. Aunque no encontraron diferencias respecto al testigo, si pudieron observar efectos fitotóxicos, por lo que sugirieron el uso de aceites más refinados, cuyas frecuencias de

6. Dentro del documento, los autores se referirán a este término mediante su acrónimo PRSV-P.

7. Los autores también se referirán a este conglomerado mediante su acrónimo.

8. Dentro del contexto del documento, para agilizar la lectura, se utilizarán solo las letras MIP. 
aplicación se hicieran en concordancia con las tasas de emisión de hojas por cada variedad y región. Para evitar fitotoxicidad, propusieron evaluar aceites más refinados para uso agrícola, como el Saf-T-Side ${ }^{\varpi}$, que incluso cuenta con registro para uso en papayo.

Además, se requiere perfeccionar la captura de áfidos en trampas tipo Moericke de diferente color para analizar si se debe incrementar su número. Del mismo modo, se debe mejorar el conocimiento epidemiológico referente al cultivo del papayo en Michoacán.

Por tanto, se evaluó el efecto de la aspersión semanal de los aceites minerales citrolina y Saf-T-SideÆ sobre la incidencia del PRSV-P en el cultivo de papayo cv. Maradol roja; para así caracterizar el progreso temporal de epidemias y compararlas con los resultados obtenidos en trabajos previos. Asimismo, se evaluó la eficiencia de captura de trampas tipo Moericke de color verde y amarillo para estimar la composición-abundancia de vectores potenciales. Estas prácticas ayudaron a explorar las posibles relaciones que guardan los vectores $y$ el ambiente con el progreso temporal de epidemias inducidas por el PRSV-P en papayo en Antúnez, Michoacán.

\section{Materiales y métodos}

El trabajo se realizó en Antúnez, municipio de Parácuaro, Michoacán, México (407 msnm, 19³0’ LN, $\left.102^{\circ} 13^{\prime} \mathrm{LO}\right)$. El vivero de papayo cv. Maradol roja se estableció el 15 de agosto de 2001 .

La semilla se depositó en charolas de 128 cavidades sobre sustrato CosmopeatÆ; luego, las plántulas se cubrieron con malla antiáfidos para protegerlas de especies potencialmente vectoras hasta el momento de trasplante, el cual se efectuó 65 días después. Se utilizó un diseño en bloques completamente al azar con una densidad de 3,735 planta/ha $(2.2 \times 1.2$ $\mathrm{m})$. Se utilizaron cuatro bloques con superficie aproximada de 30.8 x $19.2 \mathrm{~m}$; en cada uno se ubicaron 14 hileras con 16 plantas. Dentro de cada bloque se ubicó el lote experimental con 224 plantas. Cada bloque se constituyó por los tratamientos: aceite mineral citrolina, aceite parafínico Saf-T-SideÆ y testigo sin aplicación de aceite.

Los aceites se asperjaron en una concentración de $1.5 \%$, con la adición del dispersante Full Extensoræ (1 mL/L de agua). Se utilizó un aspersor manual Soloæ con capacidad de $12 \mathrm{~L}$ y boquillas de cono lleno. Se realizaron siete aplicaciones con intervalos de ocho días, que iniciaron a los 20 días después de trasplante (DDT) ${ }^{9}$. Se consideró como parcela útil a las 24 plantas ubicadas al centro del lote experimental.

Evaluación de tratamientos. La efectividad de los aceites se evaluó con base en la incidencia visual y serológica del PRSV-P, obte-

9. En el contexto del documento, las letras DDT se entienden como 'después del trasplante'. 
nida por censos de la parcela útil a los 32 y 60 DDT. Asimismo, se consideró su efecto en la altura, diámetro de tallo y número de hojas por planta a los 60 DDT.

La incidencia visual se obtuvo mediante la observación de las plantas que, a pesar de haber mostrado fitotoxicidad foliar en los tratamientos, mostraron síntomas. En cuanto a la incidencia serológica se obtuvo mediante ELISA-DAS (Enzime Linked Inmuno SorbentAssay; Agdia Inc.). La altura de planta se midió con un estadal a partir de la base del suelo hasta el grupo de hojas apicales de diferenciación más reciente.

El diámetro del tallo se midió con un vernier a una altura de $10 \mathrm{~cm}$ sobre el nivel del suelo. El conteo de hojas se realizó en forma descendente, considerando a la hoja número uno como aquella cuyo lóbulo central fue mayor o igual a los lóbulos basales de una hoja del estrato medio. La incidencia visual y serológica registrada a los 32 y 60 DDT se sometió a un análisis de varianza para un diseño en bloques completamente al azar, mediante el procedimiento GLM de SASÆ, con separación de medias (Tukey, $\mathrm{P}=0.05$ ). Posteriormente, se utilizó una prueba de T para comparar la incidencia visual y serológica en las dos fechas $(\mathrm{P}=0.05)$. Los valores de altura de planta, diámetro de tallo y número de hojas se sometieron al análisis de varianza y comparación de medias (Tukey, $\mathrm{P}=0.05$ ).
Caracterización de epidemias. Las epidemias ocasionadas por el PRSV-P se caracterizaron únicamente en el tratamiento testigo, debido a que la aspersión de aceites indujo fitotoxicidad, efecto extrínseco a la enfermedad. El progreso temporal de la enfermedad se analizó mediante el modelo de Weibull, en su forma simplificada a dos parámetros (Mora-Aguilera et al., 1996).

Para tipificar las epidemias presentes en la localidad, se estimaron los parámetros forma de la curva (c) y tasa de intensidad (b-1) con el procedimiento NLIN de SASÆ (SAS Institute, 2020), así como el inicio de epidemia (X0), fase exponencial (Ye), duración total de la epidemia (Tf), incidencia final (Yf) y el área bajo la curva del progreso de la enfermedad (ABCPE) (Rivas-Valencia et al., 2008). Los parámetros derivados del modelo de Weibull se analizaron mediante los procedimientos RANK y ANOVAÆ de SASÆ.

Composición y abundancia de áfidos. Trampas tipo Moericke (cuatro de color amarillo y cuatro de color verde) se emplearon para la captura de áfidos. Las trampas se diseñaron con recipientes de plástico de $28 \times 23 \times 18 \mathrm{~cm}$, adicionándole agua y detergente PinolÆ.

Las trampas se instalaron dentro de la plantación, en cada uno de los puntos cardinales; se ajustaron periódicamente a la altura máxima del dosel de las plantas y se realizaron trece colectas $(5,9,12,16,19,23$ y 30 de octubre; 
13, 22 y 27 de noviembre y 6, 13 y 19 de diciembre de 2001). Los áfidos capturados se cuantificaron e identificaron en el laboratorio de Entomología de la Escuela Nacional de Ciencias Biológicas del Instituto Politécnico Nacional de la Ciudad de México. Los áfidos se colectaron y ordenaron por especie, fecha, color y orientación de trampa.

\section{Monitoreo de variables meteorológicas. En} el sitio experimental se instaló una estación meteorológica integrada con una consola Weather Monitor IIÆ (Davis InstrumentsÆ) automatizada. La temperatura, precipitación, velocidad y dirección de vientos se registraron diariamente a intervalos de $2 \mathrm{~h}$.

Correlación de variables del modelo epidemiológico con áfidos colectados $\mathrm{y}$ variables meteorológicas. El análisis correlación (CORR de SASÆ) permitió estimar el coeficiente de correlación de Pearson (r), entre el progreso temporal de la enfermedad con la población de áfidos capturados. Se consideró el desfasamiento de un mes entre las capturas de áfidos acumulados durante dos semanas, respecto a la fecha de evaluación de incidencia visual de la enfermedad, con base a períodos de incubación reportados por Mora et al. (1996).

El análisis de correlación entre las variables meteorológicas y la enfermedad únicamente consideró el registro acumulado (número de horas/día) en los siguientes intervalos de temperatura $(<20,20.1$ a $23,23.1$ a $26,26.1$ a $29,29.1$ a $32,32.1$ a $34 \mathrm{y}>34^{\circ} \mathrm{C}$ ); velocidad de viento $(<2,2.1$ a $4,4.1$ a $6,6.1$ a 8 y $>$ $8 \mathrm{~km} / \mathrm{h}$ ), dirección de viento e intensidad de precipitación en $\mathrm{mm}$ totales/día a la fecha de evaluación de incidencia.

\section{Resultados y discusión}

\section{Evaluación de tratamientos}

No hubo diferencias significativas en el efecto de la aplicación de los dos aceites sobre la incidencia visual o serológica de la enfermedad, a los 32 y 60 DDT respecto a las plantas testigo (ver figura 1) (Tukey, $\mathrm{P}=0.05$ ). Además, la aplicación de ambos aceites provocó un aparente efecto fitotóxico en plantas jóvenes, que originaron quemaduras foliares.

Es probable que la aplicación de aceites minerales no sea viable en el cultivo de papayo por las siguientes razones:

a. La cobertura total del área foliar por la película de aceite se pierde rápidamente cuando se alcanzan índices de emisión foliar de papayo cercanos al máximo (0.6 hojas emitidas por día); lo que exige una protección más oportuna y completa. De acuerdo con Garrido y Reyes (2001), este índice de emisión se presenta aproximadamente entre los 45 y 70 DDT (900 unidades calor). (Ver figura 1). 
Incidencia visual

32 días después del trasplante (\%) 60 días después del trasplante (\%)

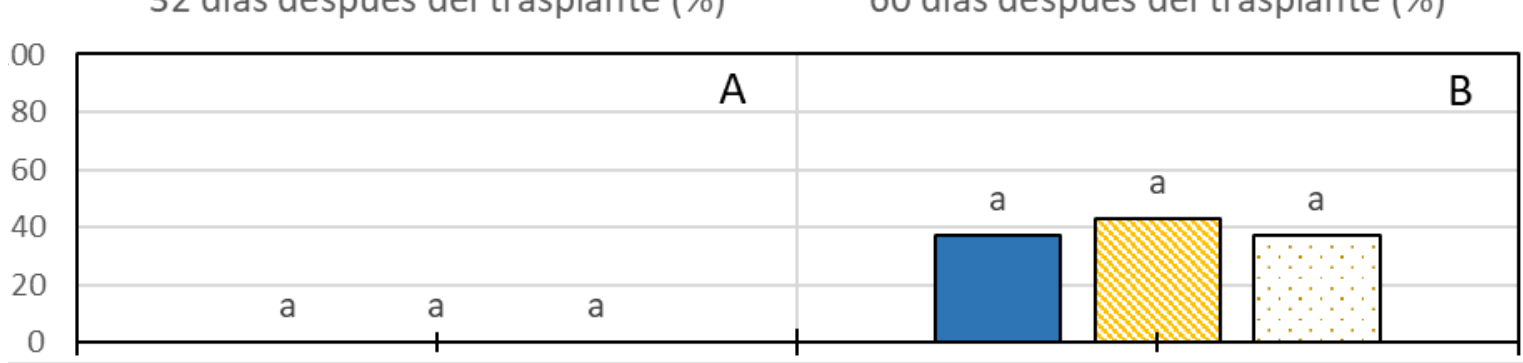

Incidencia serológica

32 días después del trasplante (\%)

60 días después del trasplante (\%)

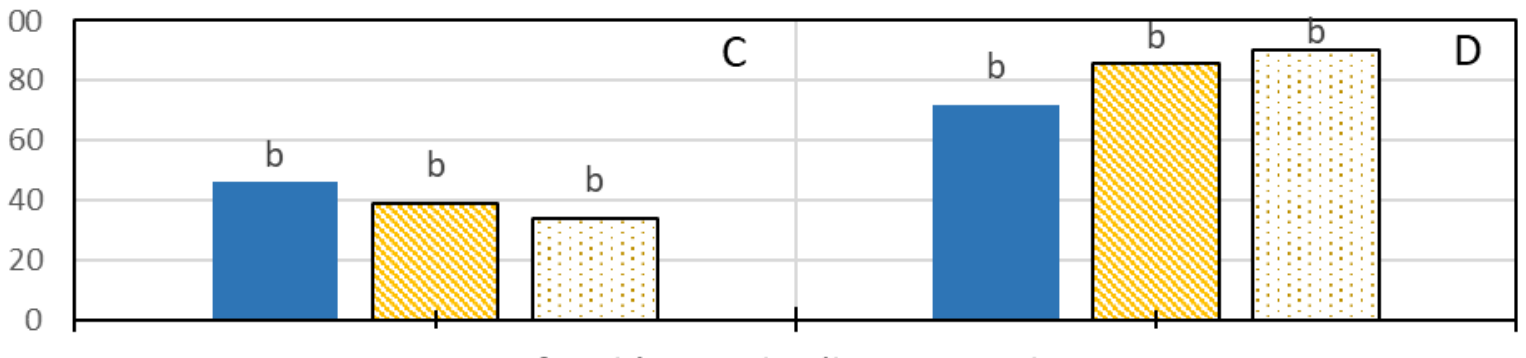

- Saf-T-Side $\square$ Citrolina $\square$ Testigo

Figura 1. Incidencia visual y serológica del PRSV-P en plantas de papayo (Carica papaya) cv. Maradol roja, asperjadas con Saf-T-Side ${ }^{\oplus}$, citrolina o sin aspersión (testigo) en Antúnez, Michoacán, México (2001). Tratamientos con la misma letra son estadísticamente iguales (Tukey,

$$
\mathrm{P} \geq 0.05) \text {. }
$$

b. Aunque las aspersiones se realicen en concentraciones adecuadas, probablemente se requiere aumentar la frecuencia de aplicaciones, quizás a 10 ó 12 aplicaciones al mes (cada tercer día) en la máxima etapa de crecimiento para garantizar la eficiencia de control.

c. La aplicación de aceites provoca efectos fitotóxicos, por lo que el aumento en el número de aplicaciones ocasionaría una mayor acumulación de los aceites en los tejidos tiernos. A pesar de que el uso de aceites minerales ha sido evaluado anteriormente en papayo (Mosqueda-Vásquez, Becerra-Leor y De los Santos-De la Rosa, 1990; GIP, 1992, 1994 y 1995; Rivas-Valencia et al., 2008), los resultados positivos al control del virus no han sido consistentes; además, en la mayoría de los casos, provocó fitotoxicidad e incrementó los costos de producción.

Los dos métodos utilizados para la evaluación de incidencia viral exhibieron resultados contrastantes. La comparación de incidencia 
visual (ver figuras $1 \mathrm{~A}$ y B), con respecto a la incidencia serológica (ver figuras $1 \mathrm{C}$ y $1 \mathrm{D}$ ) a los 32 y 60 DDT, arrojó diferencia significativa $(\mathrm{P}<0.05)$.

A los 32 DDT la evaluación visual no detectó plantas enfermas, cuando realmente existió un $40 \%$ de incidencia estimada mediante análisis serológico. De manera similar, a 60 DDT la evaluación visual exhibió 40\% de plantas con síntomas, aunque serológicamente se detectó $85 \%$ de plantas enfermas. Estos resultados sugieren que la efectividad del MIP dependerá de su implementación oportuna, respecto a la presencia de la enfermedad; la cual se debe diagnosticar de forma más oportuna, ya sea por serología o PCR.

Esto es importante debido a que una de las prácticas más recomendadas en el MIP es el desplante, que consiste en la eliminación temprana de plantas con síntomas de la enfermedad (Hernández-Castro et al., 2003, 2004). Sin embargo, tanto la detección serológica como por PCR incrementarían los costos de producción por requerir servicio de diagnóstico especializado y recursos humanos para el muestreo más frecuente y oportuno. Recientemente, Trejo et al. (2019) propusieron la medición de síntomas tempranos del PRSV-P, mediante métodos radiométricos no destructivos; lo que podría acelerar la efectividad de la detección temprana.

Las variables fenológicas número de hojas, altura de la planta y diámetro del tallo no ex- hibieron diferencias significativas $(\mathrm{P} \geq 0.05)$. En todos los tratamientos evaluados existió un efecto de reducción del área foliar (Sósol-Reyes et al., 2020), enanismo, desarrollo raquítico e inhibición de la floración. Lo anterior puede ser atribuido a la etapa temprana en que inició la epidemia inducida por el PRSV-P, tal y como lo indicaron previamente varios autores (Hernández-Castro et al., 2015); y como se demostró con el diagnóstico serológico.

\section{Caracterización de epidemias}

Las cuatro epidemias del tratamiento testigo inducidas por el PRSV-P (tabla 1) exhibieron en promedio un ajuste $\left(r^{2}\right)$ de 0.97 , forma de la curva (c) 5.15 y tasa de intensidad $\left(b^{-1}\right)$ de 0.015 .

Los primeros síntomas de la enfermedad $\left(\mathrm{X}_{0}\right)$ se observaron a los $60 \mathrm{DDT}$; la fase exponencial (Ye) tuvo una duración de 45 días y la duración total de la epidemia (Tf) fue de 72 días con incidencia final (Yf) de 98\%. El ABCPE promedio fue de 6,087 días porcentaje. Al comparar estos parámetros epidemiológicos con los obtenidos por Rivas-Valencia et al. (2008) en Michoacán, se observó que el comportamiento de la enfermedad en Antúnez fue más explosivo que en El Chauz, donde se estimó una tasa de intensidad (b-1) de 0.0092 y ABCPE de 3828 días porcentaje, aproximadamente 1.6 veces menor; aun cuando se observó que el inicio de las epi- 
demias $\left(\mathrm{X}_{0}\right)$ reportadas en su estudio se presentó a los $45 \mathrm{DDT}$.

La fase exponencial (Ye) de la epidemia tuvo una duración de 55 a 74 días y la duración total de la epidemia (Tf) fue de 87 días, con una incidencia final (Yf) de $80 \%$. Esto explide bajo porte, raquíticas, floración escasa y la variabilidad regional de la intensidad de la enfermedad. El valor de c (forma de la curva) presentó la forma típica del modelo Logístico. (Ver tabla 1). $\mathrm{CPE}=$ Área bajo la curva del progreso de la enfermedad.

\section{Composición y abundancia de áfidos}

La colecta de áfidos dentro de la plantación permitió estimar especies y cantidades presentes en la plantación, así como inferir sobre la eficiencia relativa de captura de acuerdo al color de trampa. Durante octubre, noviembre y diciembre se colectaron en total 309 áfidos correspondientes a 17 especies; cuatro de ellas potencialmente vectores del PRSV-P.

En las trampas de color amarillo se colectaron 185 ejemplares (59.9\%) y $124(40.1 \%)$ en las trampas de color verde (ver tabla 2),

Tabla 1. Parámetros epidemiológicos obtenidos mediante la caracterización de epidemias causadas en las parcelas del tratamiento Testigo por el PRSV-P en papaya en Antúnez, Michoacán, México

\begin{tabular}{|c|c|c|c|c|c|c|c|c|}
\hline $\begin{array}{c}\text { Epidemias } \\
\text { en } \\
\text { parcelas } \\
\text { testigo }\end{array}$ & $\mathbf{r}^{2}$ & $\mathbf{c}$ & $\mathbf{b}^{-1}$ & $\mathbf{X}_{\mathbf{0}}$ & Ye & Tf & Yf & ABCPE \\
\hline 1 & 0.96 & 5.16 & 0.015 & 60 & 90 & 132 & 100 & 6818 \\
\hline 2 & 0.97 & 4.72 & 0.010 & 60 & 44 & 132 & 92 & 4653 \\
\hline 3 & 0.99 & 5.47 & 0.013 & 60 & 90 & 132 & 100 & 6201 \\
\hline 4 & 0.98 & 5.26 & 0.014 & 60 & 90 & 132 & 100 & 6672 \\
\hline
\end{tabular}

Nota: $\mathrm{r}^{2}=$ Coeficiente de determinación y ajuste del modelo al modelo de Weibull $/ / \mathrm{b}^{-1}=$ Tasa de incremento de la enfermedad // $\mathrm{c}=$ Forma de la curva. $\mathrm{X}_{0}=$ Inicio de epidemia $/ / \mathrm{Ye}=$ Fase exponencial de la epidemia // Tf = Duración total de la epidemia // Yf = Incidencia final // AB- 
con diferencias significativas por especie, cies que presentaron diferencia significativa respecto al color de la trampa $(\mathrm{P}<0.05) . M$. respecto al efecto del color de trampa en su persicae, Rhopalosiphum maidis, Uroleucon captura $(\mathrm{P}<0.05)$. (Ver tabla 2$)$.

ambrosiae y Uroleucon sp. fueron las espe-

Tabla 2. Captura de áfidos (Hemiptera: Aphididae) en trampas tipo Moericke en plantación de papayo. Antúnez, Michoacán, México (2001)

\begin{tabular}{|c|c|c|}
\hline \multirow[b]{2}{*}{ Especies } & \multicolumn{2}{|c|}{ Número de áfidos ( \pm Desv. Estándar) } \\
\hline & Trampa amarilla & Trampa verde \\
\hline Aphis craccivora Koch & $0 \pm 0$ & $1 \pm 0.13$ \\
\hline Aphis fabae Scopoli & $3 \pm 0.23$ & $2 \pm 0.27$ \\
\hline Aphis gossypii Glover & $38 \pm 2.06$ & $53 \pm 2.62$ \\
\hline Aphis nerii Boyer de Foscolombe & $0 \pm 0$ & $3 \pm 0.30$ \\
\hline Aphis spiraecola Patch & $9 \pm 0.58$ & $7 \pm 0.48$ \\
\hline Capitophorus sp. & $0 \pm 0$ & $1 \pm 0.13$ \\
\hline Lipaphis erysimi Kaltenbach & $3 \pm 0.23$ & $0 \pm 0$ \\
\hline Microparsus sp. & $1 \pm 0.13$ & $1 \pm 0.13$ \\
\hline Myzus ornatus Laing & $0 \pm 0$ & $1 \pm 0.13$ \\
\hline Myzus persicae Sulzer & $24 \pm 0.85$ & $13 \pm 0.88$ \\
\hline Pemphigus sp. & $1 \pm 0.13$ & $0 \pm 0$ \\
\hline Rhopalosiphum maidis Fitch & $32 \pm 1.05$ & $19 \pm 0.90$ \\
\hline Rhopalosiphum padi L. & $0 \pm 0$ & $3 \pm 0.30$ \\
\hline Rhopalosiphum rufiabdominalis Sasaki & $41 \pm 1.55$ & $16 \pm 0.78$ \\
\hline Sitobion avenae Fabricius & $1 \pm 0.13$ & $0 \pm 0$ \\
\hline Uroleucon ambrosiae Thomas & $23 \pm 0.97$ & $4 \pm 0.33$ \\
\hline Uroleucon sp. & $9 \pm 0.55$ & $0 \pm 0$ \\
\hline Total $=309$ & 185 (59.9\%) & $124(40.1 \%)$ \\
\hline
\end{tabular}


En el caso de áfidos potencialmente vectores del PRSV-P, A. gossypii y A. nerii, se colectaron más en las trampas de color verde (58 y $100 \%$, respectivamente); mientras que $M$. persicae y A. spiraecola se encontraron más en las de color amarillo (65 y 56\%, respectivamente), aunque no se exhibieron diferencias significativas $(\mathrm{P} \geq 0.05)$.

Las especies capturadas de áfidos potencialmente vectores del PRSV-P más abundantes en total fueron: A. gossypii y $M$. persicae con 91 y 37 individuos, respectivamente. Los resultados obtenidos coincidieron con Boiteau (1990), quien demostró que los áfidos responden a longitudes de onda larga (color amarillo a verde); sin embargo, las trampas amarillas fueron más atractivas a varias especies de áfidos, principalmente aquellos que se alimentan sobre dicotiledóneas, ya que en este estudio $M$. persicae exhibió diferencias significativas $(\mathrm{P}<0.05)$ con respecto al efecto del color de trampa en la captura.

A. spiraecola y M. persicae son especies polífagas, altamente atraídas por el color amarillo, lo que representa una desventaja en estudios epidemiológicos, ya que pueden sobrestimar la actividad natural y sugieren que es importante definir el tipo de trampa a seleccionar, de acuerdo a las especies de áfidos que se desean capturar y el propósito. Webb et al. (1994) indicaron que las trampas de color verde son más atractivas que las amarillas para A. gossypii.
En este trabajo se observó que no existió diferencia significativa en densidad de captura para A. gossypii, A. nerii y A. spiraecola por color de trampa ( $\mathrm{P} \geq 0.05)$, excepto para $M$. persicae que se capturó más en las trampas de color amarillo. Al comparar la composición y abundancia de especies potencialmente vectores del presente trabajo respecto a las capturas de áfidos obtenidas por Rivas-Valencia et al. (2008) en Michoacán, únicamente coincidieron A. gossypii como la especie más abundante y la presencia de $M$. persicae y A. spiraecola, que se atribuyó a la existencia de cultivos y maleza hospederos de estos áfidos en áreas aledañas por el régimen de riego existente. No se encontró a Macrosiphum euphorbiae, a pesar que es una especie reportada como vector potencial.

\section{Análisis de correlación}

La dinámica de las poblaciones tuvo al menos un pico poblacional definido. M. persicae y $A$. nerii exhibieron un solo pico en la primera y segunda semana de noviembre, respectivamente (ver figuras $2 \mathrm{D}$ y $2 \mathrm{E}$ ). Por otra parte $A$. gossypii y A. spiraecola presentaron dos picos en la tercera semana de octubre y noviembre para la primera especie, y la primera semana de noviembre y diciembre para la segunda (ver figuras $2 \mathrm{~B}$ y $2 \mathrm{C}$ ).

Todos estos picos ocurrieron uno a dos meses antes del incremento absoluto de la enfermedad. No existen antecedentes de dinámi- 
cas poblacionales de áfidos en plantaciones de papayo de Antúnez. Sin embargo, estos resultados coinciden parcialmente con los obtenidos por Mora et al. (1993), quienes encontraron desfasamiento de un mes para el mismo patosistema con $M$. persicae, A. nerii y A. gossypii, y utilizaron estas especies para desarrollar un modelo de pronóstico para el PRSV-P en Veracruz, en conjunto con otras variables seleccionadas.

Aunque el período de captura en este trabajo fue de solo dos meses, al relacionar los cambios absolutos de incidencia visual del PRSV-P (ver figura 2A) con cada una de las especies de áfidos potencialmente vectores, considerando un mes de desfase entre las capturas de áfidos acumulados durante dos semanas respecto a la fecha de evaluación de incidencia visual de la enfermedad, se obtuvieron coeficientes de correlación significativos para $M$. persicae $(\mathrm{r}=0.8)$, A. nerii $(\mathrm{r}=0.7)$ y A. spiraecola $(\mathrm{r}=0.7)$. (Ver figura 2$)$.

A pesar de haber sido la especie más abundante durante el período de captura, A. gossypii presentó un coeficiente de correlación menor $(r=0.6)$. En Michoacán, el efecto de la precipitación, temperatura y la velocidad de viento obtenido a partir de intervalos de frecuencia dominante, respecto a la fecha de evaluación de incidencia visual del PRSV-P, aparentemente no exhibió coeficientes de correlación significativos $(r=0.3, r=-0.1$ y $r=0.1$, res- pectivamente). Es necesario continuar el monitoreo de estos insectos y variables meteorológicas durante varios ciclos en la región, tal y como se realizó en Veracruz, con la finalidad de validar resultados concluyentes.

\section{Conclusiones}

Los aceites citrolina y Saf-T-Side no redujeron la incidencia o severidad del PRSV-P en Antúnez, Michoacán; y en cambio ocasionaron fitotoxicidad foliar en papayo var. Maradol roja. La evaluación de los síntomas de forma visual fue menor a la evaluación serológica, lo que puede representar un problema para el manejo integrado del papayo.

Las aceleradas epidemias del testigo se modelaron adecuadamente con Weibull de dos parámetros. La fluctuación de las especies potencialmente vectoras, $M$. persicae, $A$. nerii y A. spiraecola obtuvieron altas correlaciones respecto a la incidencia viral.

Se agradece a los productores cooperantes Héctor Bucio y Juan Jiménez-Vargas, así como al Colegio de Postgraduados y del CONACYT, del cual provino el financiamiento parcial (Proyecto G33672-B “Bases Ecológicas Cuantitativas para el Manejo Integrado de Plagas en Papayo: Una Visión Moderna y Aplicada de Control" y beca de posgrado del primer autor). 


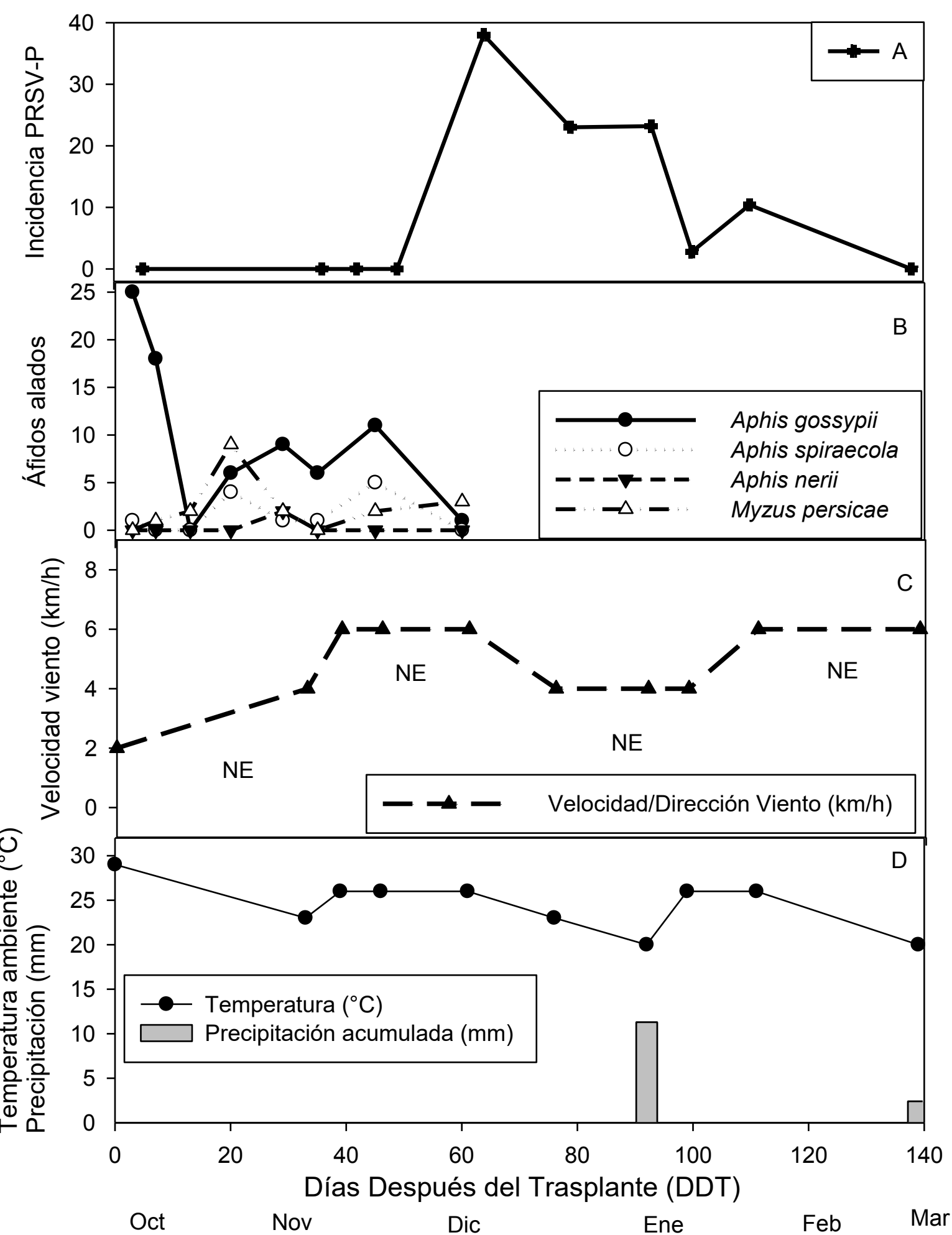

Figura 2. Incidencia del PRSV-P, áfidos (Hemiptera: Aphididae) capturados en trampas tipo Moericke y variables meteorológicas en Antúnez, Michoacán, México. A: Incidencia absoluta; B: áfidos; C: velocidad y dirección de viento dominantes; D: precipitación bisemanal acumulada y temperatura dominante. 


\section{Referencias}

Becerra-Leor, N. E. y De León-Maycotte, J. R. (1991). Evaluación de varias prácticas culturales para reducir la incidencia del Virus de la Mancha Anular del Papayo. Memorias del XIX Congr. Nac. Soc. Mex. Fitopatol. Puebla, México. p. 166.

Boiteau, G. (1990). Effect of trap color and size on relative efficiency of water-pan trap for sampling alate aphids (Homoptera: Aphididae) on potato. J. Econ. Entomol. 83, 937-942.

Cárdenas-Soriano, E. y Téliz-Ortiz, D. (1994). Caracterización de aislamientos del virus mancha anular del papayo. Agrociencia Serie Prot. Veg. 5, 103-112.

Garrido R., R. S. y Reyes D., G. (2001). Fenología de papaya Maradol bajo el esquema de "Investigar haciendo" en Yucatán. Memorias del IX Congr. Nac. Soc. Mex. Cienc. Hort. Oaxtepec, Morelos, México. p. 175.

GIP (Arenas, L.; Ávila, C.; Cárdenas, E.; Etchevers, J.; Flores, C.; García, E.; González, V., Matheis, L.; Mora, A.; Mora, G.; Nieto, D.; Riestra, D.; Téliz, D.; Velázquez, J. y Villanueva, J.). (1992). La Virosis del Papayo en Veracruz: Etiología y Control. Memorias V Reunión Cient. Sector Agropec. For. Edo. Veracruz. INIFAP. Veracruz, México. p. 62-71.

GIP (Andrade, H.; Ávila, C.; García, E.; Mora, A.; Nieto, D.; Téliz, D. y Villanueva, J.). (1994). La Mancha Anular del Papayo en Veracruz, México y su Manejo Integrado. Memorias VII Reunión Cient. Sector Agropec. For. Edo. Veracruz. INIFAP. Veracruz, México. p. 87-92.

GIP (Flores R. C.; García, E.; Nieto A., D.; Téliz O., D. and Villanueva J., J. A.) (1995). Integrated management of papaya in Mexico. Acta Hort. 370, 151-158.

Harris, F. K., and Maramorosch, K. (1977). Aphids as virus vectors. Academic Press. New York. USA. 1977. 559 p.

Hernández-Castro, E.; Riestra-Díaz, D.; Villanueva-Jiménez, J. A. y Mosqueda-Vázquez, R. (2003). Análisis epidemiológico del virus de la mancha anular del papayo bajo diferentes densidades, aplicación de extractos acuosos de semillas de nim (Azadirachta indica A. Juss.) y eliminación de plantas enfermas del cv. Maradol roja. Rev. Chapingo serie Hort. 9(1), 55-68. 
Hernández-Castro, E.; Villanueva-Jiménez, J. A.; Mosqueda-Vázquez, R. y Mora-Aguilera, J. A. (2004). Efecto de la erradicación de plantas enfermas por el PRSV-P en un sistema de manejo integrado del papayo (Carica papaya L.) en Veracruz, México. Rev. Mex. Fitopatol. 22(3), 382-388.

Hernández-Castro, E.; Villanueva-Jiménez, J. A.; Mora-Aguilera, J. A. y Nava-Díaz, C. (2010). Barreras de maíz en una estrategia de manejo integral para controlar epidemias del virus mancha anular del papayo (PRSV-P). Agrociencia, 44(3), 339-349.

Hernández-Castro, E.; Nava D., A.; Mora A., J. A.; Villanueva-Jiménez, J. A.; Vargas A., D. and Palemón F., A. (2015). Incidence of the papaya ringspot virus (PRSV-P) and management in the state of Guerrero, Mexico. In: Dimitrov, T. S., and Vitanova, I.I. Tropical Fruits. Nova Science Publishers Inc. pp. 119-127. Doi: http://dx.doi.org/10.13140/RG.2.1.3437.5203

Mora-Aguilera, G.; Nieto-Angel, D.; Teliz-Ortiz, D. and Campbell, L. C. (1993). Development of a prediction model for Papaya ringspot in Veracruz, Mexico. Plant Dis. 77, 1205-1211.

Mora-Aguilera, G.; Nieto-Angel, D.; Campbell, C. L.; Teliz, D. and García, E. (1996). Multivariate comparison of papaya ringspot epidemics. Phytopathol. 86(1), 70-78.

Mosqueda-Vásquez, R.; Becerra-Leor, N. E. y De los Santos-De la Rosa, F. (1990). Aplicación de aceites en papayo para retrasar la epidemia del virus de la mancha anular del papayo. Memorias XVIII Congr. Nac. Soc. Mex. Fitopatol. Culiacán, México. p. 93.

Rivas-Valencia, P.; Mora-Aguilera, G.; Teliz-Ortiz, D. y Mora-Aguilera, A. (2008). Evaluación de barreras vegetales en el manejo integrado de la mancha anular del papayo en Michoacán, México. Summa Phytopathol. 34(4), 307-312.

SAS Institute. (2020). SAS/STAT 15.2 User's Guide. Ed. SAS Institute Inc. Cary, N. C. USA. Recuperado de https://support.sas.com/en/software/sas-stat-support.html\#6e4aa642-2ca9483e-a72d-3b4e2940f856.

Sósol-Reyes, D.; Villanueva-Jiménez, J. A.; Osorio-Acosta, F. y Noa-Carrazana, J. C. (2020). Radial graphics to characterize PRSV-P symptoms in Carica papaya. Mex. J. Phytopathol. 38(2), 280-292. Doi: 10.18781/R.MEX.FIT.1912-1. 
Trejo P., A. J.; Villanueva J., J. A.; López C., J.; Vargas M., M. C. y Sagredo H., L. R. (2019). Estandarización de medición cercana de reflectancia en hojas de Carica papaya L. infectadas con PRSV-p. Av. Inv. Agríc. Pec. For. Acuíc. Pesq. Des. Rur. Transf. Tecnol. Biotecnol. Amb. Rec. Nat. Cambio Clim. (México). 3(1), 211-223.

Villanueva-Jiménez, J. A. y Peña-Martínez, R. (1991). Áfidos (Homoptera: Aphididae) colectados en "trampas amarillas de agua" en la planicie costera de Veracruz, México. Agrociencia Serie Prot. Veg. 2(1), 7-20.

Villanueva-Jiménez, J. A.; Osorio-Acosta, F.; Hernández-Castro, E.; Téliz-Ortiz, D.; Avila-Reséndiz, C.; Abato-Zárate, M.; Reyes-Pérez, N.; Mora-Aguilera, A.; Cano-Reyes, O.; Reta-Mendiola, J. L.; Cabrera-Mireles, H. and González-Munguía, M. V. (2019). Integrated management of papaya pests in Veracruz: Papaya ringspot virus, papaya mealybug and mites. Acta Hort. 1250, 63-68.

Webb, E. S.; Kok-Yokomoni, L. M. and Voegtlin, J. D. (1994). Effect of trap color on species composition of alate aphids (Homoptera: Aphididae) caught over watermelon plants. Fla. Entomol. 77, 146-154. 